\title{
PREGUNTAS, el cuaderno de notas de Eduardo Chillida
}

\section{PREGUNTAS, Eduardo Chillida's notebook}

\author{
Begoña FERNÁNDEZ CABALEIRO \\ Universidad Complutense de Madrid \\ bfcabaleiro@filos.ucm.es
}

\section{Resumen}

El 20 de marzo de 1994 Eduardo Chillida leía su discurso de ingreso como Miembro Honorario en la Real Academia de Bellas Artes de San Fernando. Hombre de pocas palabras, Chillida explica en la introducción a ese "discurso" las razones de su planteamiento que no responde en absoluto a un discurso tradicional sino, simplemente, al conjunto de reflexiones, preguntas, que han acompañado su vida, recogidas en su cuaderno de notas, y a las que ha ido tratando de responder a través de su obra.

Palabras clave: Chillida, preguntas, pensamientos, esculturas

\begin{abstract}
On March 20th, 1994, Eduardo Chillida read his inaugural lecture as Honorary Member of the Royal Academy of Fine Arts of San Fernando in Madrid. He was a man of few words. Chillida explains in the lecture -as well as in his notebook- the set of thoughts, reflections, questions that have accompanied his life. They were reflected in his notebook. He spent his live trying to answer these questions through his work.
\end{abstract}


Key words: Chillida, questions, thoughts, sculptures

El 20 de marzo de 1994 Eduardo Chillida leía su discurso de ingreso como Miembro Honorario en la Real Academia de Bellas Artes de San Fernando. Hombre de pocas palabras, Chillida explica en la introducción a ese "discurso" las razones de su planteamiento que no responde en absoluto a un discurso tradicional sino, simplemente, al conjunto de reflexiones, preguntas, que han acompañado su vida, recogids en su cuadernos de notas, y a las que ha ido tratando de responder a través de su obra:

Con este pequeño texto que les voy a leer no pretendo ofrecer ni encontrar respuestas que expliquen el proceso de mi obra, sino más bien mostrar brevemente algunas dudas e interrogantes que me han acompañado a lo largo de toda mi vida como escultor, con la esperanza de que tanto mis esculturas como la contestación de mi gran amigo don José Antonio Fernández Ordóñez puedan clarificar alguna de ellas. ${ }^{1}$

\section{Arte, artistas y corrientes artísticas}

Chillida se plantea los problemas que surgen en su obra como preguntas y trata de responder. En 1948 Chillida llega a París. Realiza las primeras piezas en yeso.

Chillida se ha declarado gran admirador de Grecia, de la claridad, de la democracia y de tantas cosas que ha enseñado este pueblo en la historia. Grecia era un alimento muy deseable para el artista, según sus propias palabras, sin embargo, llegó un momento en que dejó de ser conveniente para él apartándose entonces radicalmente del arte griego:

El arte griego lo conozco muy bien; pero en esos años dejé de verlo. ${ }^{2}$

El artista reconoce que en sus primeros trabajos hay un total de doce o trece obras figurativas que estaban vinculadas con la estética griega arcaica, la primera escultura griega, las Korés, los Kouros del siglo VI antes de Cristo, lo

${ }^{1}$ Chillida, E., Preguntas, Real Academia de Bellas Artes de San Fernando, Madrid, 1994. Introducción.

${ }^{2}$ Chillida, E., «Un hombre que se hace muchas preguntas», Nuestro Tiempo 461 (1992), pp. 50-51. 
preclásico. Cuando Chillida ve que debe apartarse de lo griego trabaja hacia adentro afianzando su línea fundamental. En el momento en que vio que esto había ocurrido, Grecia dejó de ser peligrosa para él, "ya no tenía poder (...) de torcerme". Entonces realizó junto a su esposa un viaje a Londres para volver a ver el British Museum, sus obras griegas, las Parcas, Fidias...

en las obras griegas del British de Londres me volví a encontrar, y sin perder para nada mi línea fundamental, con un nuevo componente que ya estaba en mis torsos pero ahora potenciado por una nueva visión que proporciona la circunstancia de estar mirando desde un punto de vista diferente. ${ }^{3}$

A continuación Chillida realizó algunos tanteos en la piedra, el granito, la madera... El hierro es el material con el que mejor se comunicaba. Su primera escultura en hierro la realizó en el año 1951, una estela funeraria a la que puso el nombre de Ilarriak. Ilarriak fue su primera obra no figurativa. Los plasticismos de Chillida nacen siempre de su postura frente a tantas incógnitas:

Quiero conocer y, mi manera de hacer esta indagación en lo desconocido es dando estos pasos que son mi obra. ${ }^{4}$

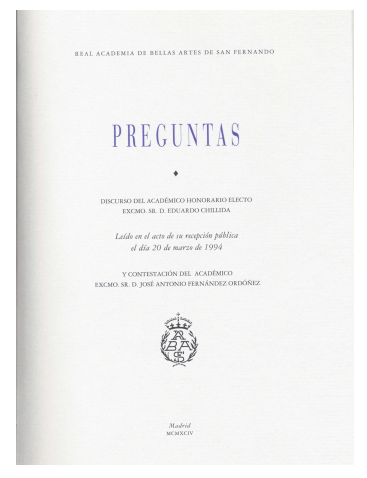

"La obra es una manera de fraguar, de materializar mis preguntas" trabajo está saturado de un profundo respeto hacia la materia, su comportamiento, su conducta. Dominar la materia es parte fundamental de su trabajo pero, dominarla de manera respetuosa, no tiránica, en una relación constante que la hace depender del tiempo y la velocidad:

\footnotetext{
${ }^{3}$ Ibidem, p. 51.

${ }^{4}$ Ugalde, M. Hablando con Chillida, escultor vasco, San Sebastián, Txertos, 1975, pp. 68-69.

${ }^{5}$ Ibidem, p. 134
} 
El espíritu, una materia rapidísima (...), la materia, eso, un espíritu lento. ${ }^{6}$

En este punto es importante también señalar la relación de Chillida con Brancusi, considerado el escultor más grande de su generación y uno de los padres de la modernidad escultórica que se desarrollaría a lo largo del siglo XX.

Formalmente las obras de Chillida son muy distintas de las de Brancusi y, sin embargo, a través de la obra de ambos se estableció una comunicación íntima y profunda. Cuando Chillida vio por primera vez a Brancusi pudo darse cuenta de que su comportamiento con relación a la obra que hizo y a su vida tenía una coherencia especial, sobre todo comparada con la vida y obra de sus contemporáneos. Chillida vio en Brancusi una mayor coherencia en sus relaciones con la obra y con la materia, con la sociedad, con el trabajo. Brancusi era un hombre comprometido. Su conducta estaba guiada por una serie de normas muy rigurosas que acaso no se apreciaban a primera vista pero que, observando su comportamiento personal, a través de él se llegaba a la obra realizada mediante una depuración y un rigor especial. Ante su obra, Chillida se plantea de dónde viene ese rigor y lo explica afirmando que viene de un comportamiento especial, no solamente estético sino de raíces profundas. Brancusi es para Chillida,

un hombre que rumia mucho y que no da un solo paso fuera de una normativa de comportamiento muy riguroso y, a la vez, muy respetuosos de todo lo que encuentra en todos esos caminos que tiene que recorrer. ${ }^{7}$

Cuando Chillida y Brancusi se conocieron se dio una inmediata comunicación entre ambos,

tan pronto comencé a comunicarme con él me di cuenta de que lo que había notado a través de su obra era verdad. En este hombre, en este artista, percibí yo, acaso por primera vez -aunque ya había leído a Teilhard de Chardin, quien valora y dignifica una materia-, en este hombre, en Brancusi, percibí yo que hace lo mismo que Teilhard de Chardin: trata a la materia con un gran respeto. ${ }^{8}$

\footnotetext{
${ }^{6}$ Ibidem, p. 107

${ }^{7}$ Ibidem, p. 59.

${ }^{8}$ Ibidem, p. 61.
} 
Chillida considera que Brancusi escucha la llamada de la materia como materia que no va a ser solamente vehículo de un pensamiento o una idea; la densidad de los materiales, las relaciones de tiempo y espacio, en definitiva, el comportamiento total de la vida entera integra la obra.

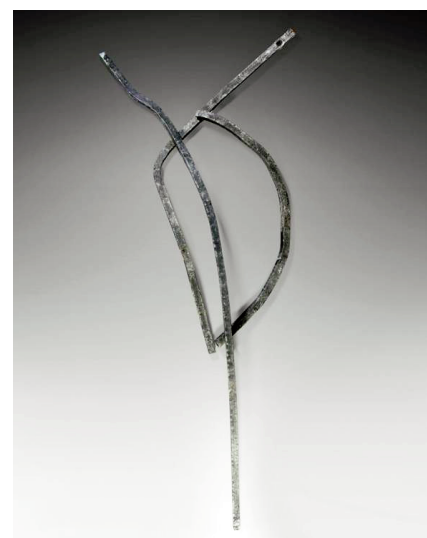

Brancusi. La señal, 1928-29

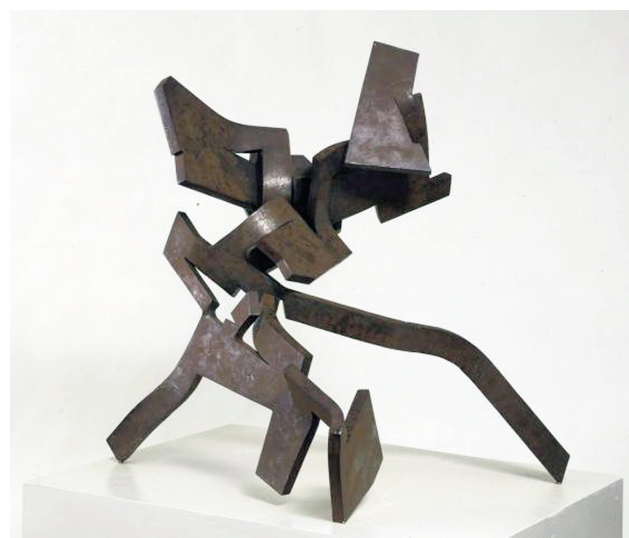

Chillida, Rumor de límites $I V, 1960$

La sensación de comunicación y afinidad con Brancusi que experimentó Chillida fue similar a la experimentada ante la obra de Medardo Rosso, escultor italiano contemporáneo de Rodin. Rosso es un artista distinto de Chillida y Brancusi. No hay ninguna comunicación formal entre ellos pero hay una circunstancia fundamental que los pone en contacto, los tres creen en la exigencia de un tipo de comportamiento con relación a la obra hecha,

son ellos los que me han ayudado a percibir y a creer en este fenómeno?

Chillida tuvo la fortuna de coincidir con numerosos supervivientes de una prolífica generación anterior. Cultiva la amistad con Giacometti, Braque, Dupin, Clayeux, Miró, Sert, Calder... A Picasso lo califica como "el mejor" y a Noguchi como "el mejor decorador del mundo"

Chillida -afirma Juan Daniel Fullaondo- es el creador menos dadaísta del mundo. No hay humor en su obra. Es un testimonio de resonancias bíblicas mucho más próximas al Eclesiastés que a Duchamp. En un mundo regido por la ingeniosidad, Chillida deviene un profeta solitario, un extraño, la voz que clama en el desierto. Acumulando todos los triunfos del mundo pero en solitario. ${ }^{11}$

\footnotetext{
${ }^{9}$ Ibidem, p. 39.

${ }^{10}$ Ibidem, pp.39-40.

${ }^{11}$ Ibidem, p.80.
} 


\section{Pensamiento, filósofos, relaciones}

En el escultor es constante la búsqueda de respuestas a sus preguntas y esto le llevará no solo a mirar a otros artistas sino también a relacionarse con filósofos, místicos, científicos. Cualquier campo del saber que pueda arrojar algo de luz a esas "preguntas" que rumia constantemente, es importante para él.

En el terreno de la filosofía son amplias sus relaciones con los existencialistas de finales del siglo XIX y principios del XX, por ejemplo. Kierkegaard es para Chillida "un hombre que dice siempre lo mismo, pero, analiza, un hombre que dice la verdad dice siempre lo mismo" y cita también, como fuente de pensamiento para él, la frase del danés,

no se trata más que de buscar el lugar donde hay que ver (porque) yo lo que quiero es despejar las incógnitas. Quiero conocer y, mi manera de hacer esta indagación en lo desconocido es dando estos pasos que son mi obra. ${ }^{12}$

Chillida se plantea los problemas que surgen en su obra como preguntas y trata de comprender.

En este terreno del pensamiento Bergson es también importante para el artista, Bergson es para Chillida uno de los hombres que más ha profundizado en los temas del "tiempo" y el "espacio" planteando el tema del "tiempo" como incógnita. Es considerado por Chillida como el filósofo que ha tenido quizás las intuiciones más geniales en este terreno.

El problema del "tiempo", de la "duración", plantea para Chillida una serie de misterios que están ahí. Mucha gente se los salta pero, el que reflexiona seriamente, se los plantea siempre. El hecho misterioso de la no dimensión del presente, que es donde todo ocurre; el hecho de que el futuro y el pasado son contemporáneos... Todo este tipo de problemas son los que están subyacentes en su obra. El encuentro Chillida-Bergson fue a través de la obra Dimensión creadora. Antes de entonces había leído algunas citas pero no había tenido oportunidad de leerlo completo. Le resultó difícil pero de gran interés, tanto que llegó a leerlo varias veces.

¿Cómo es posible que nuestra vida, formada por sucesivos presentes que no tienen dimensión, pueda durar veinte, cuarenta u ochenta años?

¿Qué clase de tiempo conduce a esa duración? ${ }^{13}$

\footnotetext{
${ }^{12}$ Ibidem, pp. 68-69.

${ }^{13}$ Chillida 1994, op. cit. (nota 1), p.37.
} 
Heidegger y Chillida se conocieron en el año 1967, en la visita a una exposición de la galería Erker en St. Gallen. Heidegger entonces se había interesado por diversos artistas como Henry Moore, Giacometti y también el propio Chillida. En ese encuentro mantuvieron una conversación en la que Heidegger siempre hablaba en alemán traducido por un alumno. Esto ponía de manifiesto la preocupación del filósofo por expresarse en la lengua que mejor conocía, donde dominaba los matices, dejando al traductor la responsabilidad de los cambios que se producen en toda traducción. Hablaron sobre cuestiones de "tiempo", "espacio"... y Chillida envió sus propias notas y reflexiones a este filósofo. Cuando volvieron a encontrarse Heidegger comentó a Chillida que estaba escribiendo un libro sobre el arte y el espacio que llevaría después precisamente este título, L'art et L'space, traducido al francés por Jean Beaufret y Francoise Fedier. El texto, muy breve, estaría ilustrado por Chillida.
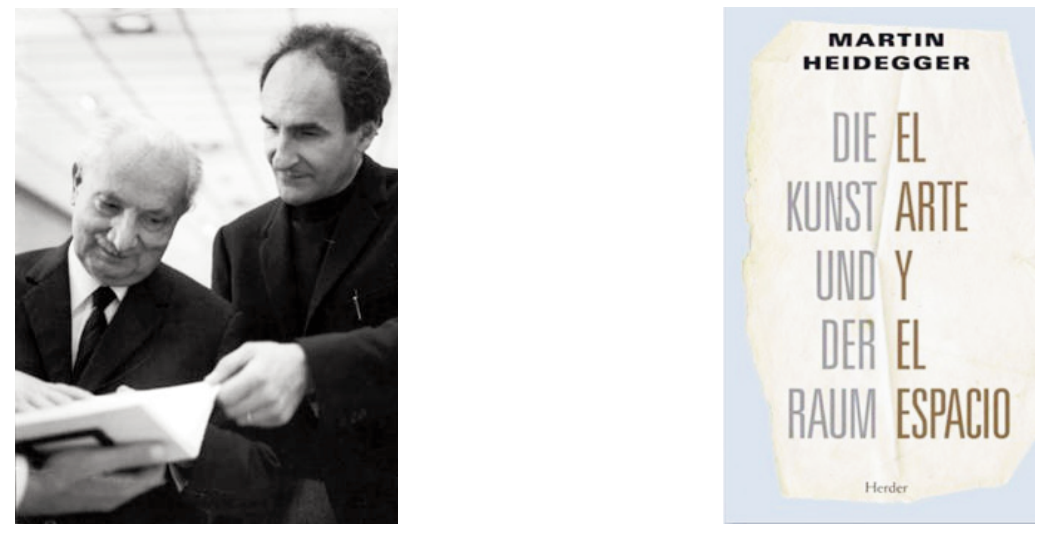

Este breve ensayo en versión bilingue alemán-español apareció originalmente en el otoño de 1969, en una edición limitada de 150 ejemplares para bibliófilos, publicada por la galería Erker, de St. Gallen. Se trataba de una colaboración artística entre el filósofo y Eduardo Chillida, al que Heidegger había conocido un año atrás, en uno de los célebres encuentros entre escritores, pensadores y artistas que organizaba la galería suiza. La obra contenía un disco con la grabación del texto leído por el propio Heidegger y un manuscrito original en litografía escrito por el filósofo sobre pizarra de Solnhofen que acompañaba a siete litho-collages de Chillida.

En calidad de documento bibliográfico, la cuidada edición de este texto, tan breve como sugerente, resulta un punto de partida vital para entender, en ambos, la concepción del espacio, de la tierra, del mundo, de la materia, del ser.

En este contacto con Heidegger para Chillida fue una sorpresa descubrir la preocupación del filósofo alemán por algunas cuestiones que para él eran vita- 
les y que estaban encarnadas en su obra. Los conceptos de "lugar" (leku), "espacio-lugar", "localización" (topos) y "encuentro", "límite", "lugar de encuentro"... son utilizados por Heidegger en este trabajo, pero alguno de ellos había sido utilizado por Chillida incluso como título de sus obras mucho antes de aparecer este libro. Estos son conceptos que toca el texto de Heidegger, con quien se encuentra Chillida en su pensamiento, aunque más desde el punto de vista artístico que filosófico.
¿No es la geometría únicamente coherente cuando el punto no tiene medida?
Este punto, para que todo funcione, necesita no tener medida y sin embargo ocupar un lugar.
¿Se puede ocupar un lugar sin tener medida?
Únicamente en la mente esto es posible.
¿Existe algo sin medida en el Universo?
¿Es la medida condición necesaria para formar parte del Universo?
¿Es el presente sin medida parte del Universo?
Si el presente tuviera medida ¿no estarían disociados por ella el pasado y el futuro? ¿Qué sería de la vida, de la palabra y de la música?
¿No es la no dimensión del presente lo que hace posible la vida, como la no dimensión del punto hace posible la geometría? ${ }^{14}$

Heidegger dice por ejemplo, que lo que el artista produce son cuerpos, que la hechura de un cuerpo de estos, una escultura, tiene lugar en una limitación que es a la vez una inclusión y una exclusión con respecto al límite. Es entonces, en esas limitaciones del espacio, donde entra en juego ese espacio ocupado por la forma plástica y que recibe su marca como un volumen cerrado, un volumen perforado de apertura y un volumen vacío. Heidegger sabe que éste es un hecho aparentemente fácil, fácil de comprender, pero, a la vez, lleno de enigmas; y distingue muy bien entre la forma distinta de considerar el espacio que tiene el arte y la técnica científica. Ambas maneras de considerar son muy diferentes porque parten de intenciones distintas y el juicio se realiza mediante procedimientos distintos a pesar de que, en última instancia, el espacio sea el mismo, "aquel que recibió su primera determinación de Galileo y Newton". El espacio sujeto a leyes físicas. Un espacio determinado y sujeto por y de una manera física, cuyas leyes ya conocemos. Heidegger sabe que no puede hacer otra cosa más que preguntar estas preguntas que solo hace el hombre, ¿Cuál es

${ }^{14}$ Ibidem. 
la propiedad del espacio?, ¿cuál la del espacio del arte?, ¿cuál es la modalidad plástica más afín a esa limitación espacial?, ¿conoce el arte contemporáneo a algún artífice creador que haya aprehendido esta propiedad del espacio y la haya reflejado adecuadamente en la obra consumada?

El diálogo limpio y neto que se produce entre la materia y el espacio, la maravilla de ese diálogo en el límite, creo que, en una parte importante, se debe a que el espacio, o es una materia muy rápida, o bien la materia es un espacio muy lento. ¿No será el límite una frontera, no solo entre densidades, sino también entre velocidades?

¿No será la densidad, en todo su esplendor, necesaria para tratar de comunicar, de entender, de oír el espacio?

¿No se hace el agua viva rebelándose contra la horizontal y al mismo tiempo buscándola? ${ }^{15}$

\section{Místicos poetas}

\section{San Juan de la Cruz en compacto}

La mística de la poesía de san Juan de la Cruz viaja desde la Castilla del siglo XVI para instalarse en un compacto traducida al euskera. El cantautor vasco Imanol y el músico Karlos Giménez han trabajado durante tres años para poner música a la traducción de los 'Cánticos espirituales' que Go orese realizó el poeta Nicolás Ormaetxea. La puesta al día del lirismo de san Juan de la Cruz cuenta con el apoyo de las voces de 12 miembros del Coro Easo de San Sebastián, además de música de piano, bajo, saxo, flauta, música de cuerda y una carátula firmada por Eduardo Chillida. En 'Barne kanta'todos se han 'Burne kanta' todos se han grave de Imanol para recrear los matices de la poesía mística en el tramo final del siglo

Es notable también la influencia de místicos y poetas en la obra de Chillida. Santa Teresa, los libros de mística en general, desde los alemanes Eckhart, Henri Suso y Jacob Boheme, hasta San Francisco de Asís, San Juan de la Cruz. Entre los orientales, Lao Tse. También poetas franceses como Rimbaud, Baudelaire, Paul Valery o vascos como Unamuno y Baroja.

${ }^{15} I d .$, p.39 
¿Existen límites para el espíritu?

Gracias al espacio existen límites en el Universo físico y yo puedo ser escultor.

¿Qué clase de espacio hace posibles los límites en el mundo del espíritu? ¿No son la construcción y la poesía componentes esenciales de todas las artes? ${ }^{16}$

El tema de la gravedad, por ejemplo, refleja estas influencias. "La gravedad" siempre preocupó a Chillida. Posiblemente sus lecturas místicas han influido en esto, santa Teresa, san Juan de la Cruz y otros místicos indios. Como consecuencia de este interés por la fuerza de la gravedad, surgió el interés por el opuesto a la gravedad, o lo que Chillida denomina "levitación", algo que se rebela contra ella. Así, la obra de Chillida comienza a ir en la dirección de adquirir mayor densidad. Mayor peso para, precisamente desde ahí, -al contrario de muchos artistas que para plantearse el tema de la levitación procuraron eliminar el peso, emplear elementos livianos o de poco peso- plantear de cara el problema de la gravedad, para lo cual "hay que partir del peso". Para plantear de fondo el problema de la gravedad, no se puede partir de aquello donde la gravedad no actúa, sino de aquello donde la gravedad actúa de manera máxima, extrema. Por eso, al límite de esa evolución, Chillida llega a esas esculturas enormes de hormigón, suspendidas, acaso en función de una de las imágenes mentales que se han venido formando con la experiencia que tenemos del hormigón armado. Aquí se plantea el problema de la serie de esculturas "lugar de encuentro". En estas esculturas Chillida cree haber invertido el problema: plantea el problema del espacio al revés, es decir, que en el momento en el que una escultura de éstas está apoyada en el suelo y la levantas, se invierten todos los problemas porque, a nivel mental, de imaginación y de materia, y del espacio y del tiempo, es ya el espacio el que sustenta a la escultura de hormigón que pesa veinte toneladas, es el espacio el que sustenta a nivel real.

Madrid. Museo al Aire Libre. Calle Juan Bravo/ $/ \mathrm{P}^{o}$ de la Castellana. Inaugurado el paso elevado en 1970, pronto surge la idea de crear un museo de escultura moderna en la zona inferior del mismo de las muchas conversaciones mantenidas por los ingenieros y el artista Eusebio Sempere.

Aunque la propuesta era quizá demasiado novedosa, sin embargo tuvo una buena acogida por parte de las autoridades municipales, sobre todo porque el obstáculo económico que suponía la compra de las esculturas, quedaría resuel-

${ }^{16}$ Ibidem, p. 38. 
to mediante la donación de las mismas por parte de los autores o de sus familiares, gracias a la amistad que les unía a todos ellos con Sempere.

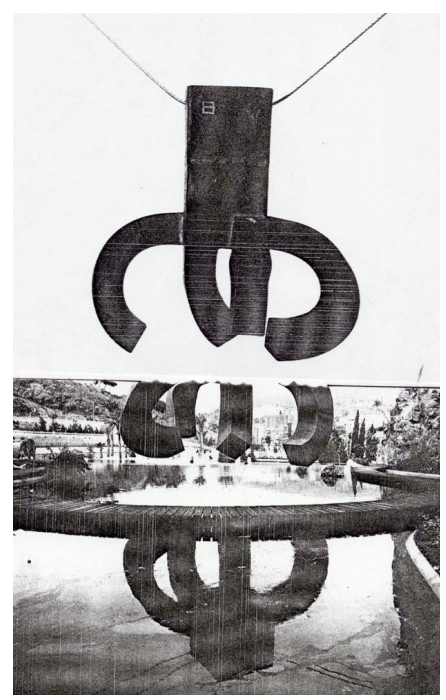

Elogio del agua, 1987

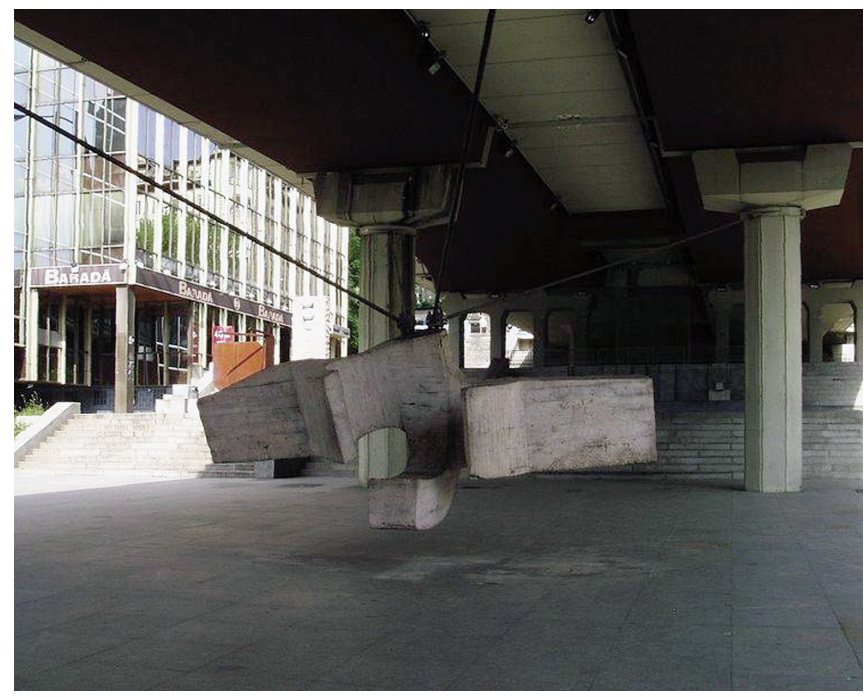

Lugar de Encuentros (También conocida como La sirena varada)

Sin esta generosa contribución de los artistas hubiera sido impensable reunir semejante conjunto de obras, muchas de ellas realizadas expresamente para el Museo, haciéndose cargo el Ayuntamiento sólo de los gastos de materiales e instalación. El proyecto quedó aprobado en el verano de 1971.

El propósito del Museo, según José Antonio Fernández Ordóñez, era recuperar un espacio urbano para uso común, convirtiéndolo en zona de paso, descanso y esparcimiento y acercar al público el arte abstracto español, hasta el momento escasamente conocido. Esta iniciativa está en relación con el Museo de las Casas Colgadas de Cuenca, fundado en 1966.

Aunque el Museo se abrió al público en 1972, la inauguración oficial no se pudo llevar a efecto debido a la polémica que desencadenó el montaje de La sirena varada de Chillida, especialmente creada para quedar suspendida de los pilares del puente. La postura que adoptó el Ayuntamiento durante la etapa del Alcalde Arias Navarro, fue la rotunda oposición a que esta obra se colgase del puente, alegando razones de seguridad por el peso excesivo de la misma, sin atender a los informes realizados por los ingenieros responsables, que no tenían ninguna duda sobre la resistencia del paso, llegando a adquirir esta situación una trascendencia política. Como consecuencia de ello, la escultura de Chillida fue retirada en abril de 1973 del Museo y empezó un largo peregrinaje, al que puso fin el alcalde José Luis Alvárez en 1978, tomando la decisión de 
colgarla definitivamente en su emplazamiento original, tras haberse realizado un profundo estudio de las condiciones técnicas de la obra de ingeniería. La sirena varada, con sus 6.150 kilos de hormigón quedó por fin instalada el 2 de septiembre de 1978.
Al alba conocí la obra. Puede ser de mil maneras, pero sólo de una.
¿No es el camino el que, desde la libertad, nos conduce a la percepción?
¿No es el arte algo que le ocurre al hombre ante sí mismo y ante un testi- go implacable: la obra?
¿No es entre el ya no y el todavía no donde fuimos colocados?
¿No será el arte consecuencia de una necesidad, hermosa y difícil, que nos conduce a tratar de hacer lo que no sabemos hacer?
¿No será esta necesidad prueba de que el hombre no se considera terminado?
¿No será el paso decisivo para un artista el estar con frecuencia desorientado? ${ }^{17}$

\section{El artista y la ciencia}

El alimento para el artista surge de fuentes variadas. Chillida ha llegado a afirmar: "Yo debo quizás más a la ciencia que al arte", aunque añade,

de la muerte, la razón me dice definitiva. De la razón, la razón me dice limitada. ${ }^{18}$

La biología es quizá la ciencia que más le interesa,

porque es una ciencia que trata de las leyes de la vida y, por tanto, un artista no puede encontrar mejor maestro ni mejor alimento. ${ }^{19}$

La Física es para él una ciencia más difícil, más difícil por su lenguaje mismo. Le resulta arduo entrar en esta ciencia con cierta holgura a pesar de haber estudiado matemáticas (Ciencias Exactas) durante dos años,

¿Cuál es la diferencia entre la ciencia y el arte?

Copérnico demuestra que Ptolomeo estaba equivocado. Einstein hace lo

\footnotetext{
${ }^{17}$ Ibidem, pp. 38-39.

${ }^{18}$ Ibidem, p. 43.

${ }^{19}$ Ugalde 1975, op. cit. (nota 4) 101.
} 
propio con Galileo. Lo que yo me pregunto desde el arte es lo siguiente: ¿Por qué Goya con su obra no demuestra ni necesita demostrar que Velázquez estaba equivocado? $?^{20}$

Las Matemáticas, arduas igualmente, son con La Física, alimento también de su reflexión. Frecuentemente mantiene contactos y cambios de impresiones con matemáticos reconocidos en su campo de trabajo. En marzo de 1994 él mismo reconocía en una mesa redonda celebrada en la Fundación Cultural Central Hispano de Madrid que "estas ciencias trabajan y se cuestionan sobre conceptos como "espacio", "tiempo", "movimiento"..., conceptos de gran importancia en la obra de Chillida.

ESPACIO: "Yo no entiendo casi nada y me muevo torpemente, pero el espacio es hermoso, silencioso, perfecto.

Yo no entiendo casi nada, pero comparto el azul, el amarillo y el viento (...). ¿No es el límite el verdadero protagonista del espacio, como el presente, otro límite, es el protagonista del tiempo?’”21.

TIEMPO: "No vi el viento

Vi moverse las nubes.

No vi el tiempo

Vi caerse las hojas.

No se debe olvidar que el futuro y el pasado son contemporáneos

La tarde avanza lentamente, y yo mirando quiero ver ${ }^{22}$.

En el año 1958 Eduardo Chillida ganaba en Estados Unidos el Premio Graham, uno más en una amplia lista. A raíz de este premio participó en un seminario con distintas personalidades de diversas disciplinas con el fin de discutir el problema de la integración de las artes. Aquí tiene la oportunidad de hablar con Paul Wise, biólogo que curó a Eisenhower, y le plantea temas que le inquietan como "las interrelaciones, por ejemplo, o el hecho de que sobre todas las leyes parciales hay una ley superior que abarca a todas, ¿Por dónde se relacionan esas leyes parciales? Wise le dio una interesante respuesta:

Ustedes los artistas y los poetas hacen estas preguntas y olvidan que nosotros los científicos llevamos como los caballos, unas anteojeras, no

\footnotetext{
${ }^{20}$ Chillida 1994, op. cit. (nota 1), p. 40.

${ }^{21}$ Ibidem, pp.42-43.

${ }^{22}$ Ibidem, pp. 43-44.
} 
podemos distraernos: todas estas llamadas a la libertad, a la penetración, que hacen los artistas nos están vedadas... ${ }^{23}$

Creo que el ángulo de $90^{\circ}$ admite con dificultad el diálogo con otros ángulos, sólo dialoga con ángulos rectos.

Por el contrario, los ángulos entre $88^{\circ}$ y $93^{\circ}$ son más tolerantes y su uso enriquece el diálogo espacial.

¿No son por otra parte los $90^{\circ}$ una simplificación de algo muy serio y muy vivo, nuestra propia verticalidad? ${ }^{24}$

\section{El hombre en Chillida}

La base de las preguntas que se hace Chillida constantemente a lo largo de su vida y de su obra, tiene como fondo aquellos conceptos fundamentales a los que trata de responder y que, de alguna manera, van construyéndose con una configuración propia en el hombre y artista:

El hombre comienza a hacerse desde dentro, desde muy adentro, a partir de su singladura vital, desde antes de romper a llorar, colgado del cordón umbilical de su madre. Yo me he estado formando, conformando, haciendo, madurando, desde muy antes que mis paseos solitarios por las rocas de Igueldo... ${ }^{25}$

El arte no se puede enseñar, hay que aprenderlo. Chillida afirma que no cree en la enseñanza del arte. Cree en cambio, que un artista lo que hace es aprender. El profesor no es el que ha de enseñar sino que es el que está con él, el que tiene que aprender.

Esta es una distinción fundamental que hay que tener en cuenta para comprender el camino de un artista. El artista trabaja buscando sin saber hasta qué parte del camino va a llegar algún día. A diferencia del técnico que es aquel que sabe lo que tiene que hacer desde el principio y lo hace perfectamente. El artista indaga, inventa y tropieza. El técnico se repite, realiza a la perfección a veces, pero aquello que ya está inventado.

\footnotetext{
${ }^{23}$ Ugalde 1975, op. cit. (nota 4) p. 101.

${ }^{24}$ Chillida 1994, op. cit. (nota 1), p. 44.

${ }^{25}$ Ugalde 1975, op. cit. (nota 4), p. 63.
} 
A un artista lo distingue precisamente esa función de riesgo que asume, tiene que dar unos pasos muy arriesgados, tiene, en el fondo y definitivamente, que hacer lo que no sabe hacer (...). El técnico es un hombre que es útil para la humanidad, quién lo niega, pero es un hombre que no hace nada más que aplicar los conocimientos que están ahí, y el técnico entonces, será competente en la misma proporción en que sepa hacer mejor una cosa (...), una cosa concreta, mientras que a un artista que sabe hacer perfectamente una cosa le nace muerta. ${ }^{26}$

Chillida es partidario de un desarrollo para el hombre, en beneficio del hombre. Nada en contra de éste, ni en su dimensión física ni en la espiritual. Ve al hombre desde una perspectiva fundamentalmente espiritual que está en la raíz, en el primer aliento del hombre. De ahí que conceda una gran importancia tanto a la libertad de los pueblos como a la libertad individual,

Así como no permito que nadie decida por mí los fundamentos de mi vida espiritual y cultural y social en lo personal, tampoco puedo admitir que nadie, por grande que sea, por poderoso que sea (...) me pueda hipotecar lo que es mío personal, íntimo y fundamental. Debemos esforzarnos en tener conciencia del valor que tiene lo nuestro para nosotros, sobre todo para nosotros. ${ }^{27}$

Chillida entiende la cultura como la forma personal que tiene un pueblo para enfrentarse a la realidad, en su forma propia que es distinta de la de otro. En cuanto a la cultura vasca, la define como el modo de hacer frente, a su modo, a un modo personal que nadie puede negarles, a una realidad que es también muy personal. Y, sin desolidarizarse con los demás pueblos sino al contrario, comprometiéndose con ellos en la solidaridad, que tiene que ser recíproca, y también en la libertad del respeto a todos.

Su visión de la vida es cosmopolita a la vez que vasca; un sentido de la vida que no debe estar limitado a su propio mundo sino abierto al resto del mundo:

Yo produzco. Mi propio trabajo está conectado al trabajo de otras gentes que han trabajado antes que yo. Tal vez sin conexión con el arte pero conectados a través de su manera de comprender la vida. He aprendido muchísimas cosas fuera de mi País Vasco y fuera de nuestra cultura pero

\footnotetext{
${ }^{26}$ Ibidem pp. 120-121.

${ }^{27}$ Ibidem, p. 163.
} 
incluso esas cosas que he aprendido fuera de nuestra cultura han sido asimiladas con una mentalidad vasca. ${ }^{28}$

Sin embargo Chillida supo encontrar su lugar, aquel en el que el artista vive con la paz y condiciones precisas para realizar plenamente su obra. Es lo que él llama "mi sitio", el País Vasco,

Los vascos (...), una manera distinta de acercarse a la vida. Una gente tan fuerte, tan delicada, perteneciente a una antigua cultura... de momento estamos donde estamos pero debemos conocer nuestros límites:

A mi viejo pueblo,

A mi joven patria,

Ofrezco mi obra

Con todo mi corazón. ${ }^{29}$

Junto a las cuestiones relacionadas con su origen en su propio espacio, en su propia tierra, Chillida plantea cuestiones universales desde los límites de su propia razón:

La verdadera importancia de la razón reside en el poder que tiene de hacernos comprender sus propias limitaciones. ${ }^{30}$

Ésta es la conclusión a la que llegó Chillida, su postura de valoración de la razón misma, tras superar la crisis razón-fe.

De la muerte, la razón me dice:

definitiva.

De la razón, la razón me dice:

Limitada $^{31}$.

La ética, en el sentido más recto de la palabra, tiene una relación muy directa y estrecha con su obra. Chillida no admite la estética sola, como el solo poder de las apariencias, de las formas solas ni de los colores solos, sino que

\footnotetext{
${ }^{28}$ Boulting, L. Arte español del siglo XX (Serie visual), Leeson W. Production.

${ }^{29}$ Ibidem.

${ }^{30}$ Ugalde 1975, op. cit. (nota 4) p 140.

${ }^{31}$ Chillida 1994, op. cit. (nota 1), p. 43.
} 
cree firmemente que todo eso se da como una consecuencia de algo cuyo motor ha sido primero de orden ético. Lo estético para Chillida puede ser una especie de prolongación de lo religioso y lo ético. Dios es una presencia en su obra, en su proceso creador, en su vida, una presencia reconocida por el artista como una constante:

Yo lo siento como aquello que está cerca y lejos, al final, el todo; sí, esa suma que es el camino más grande que todos los pasos de un hombre y de todos los hombres juntos. ${ }^{32}$

En esa misma línea, el final de la vida -o la muerte- es la Vida, una vida que es capaz de contener la muerte, esa muerte que "cuando yo estoy, ella no está, y cuando ella está yo ya no estoy".

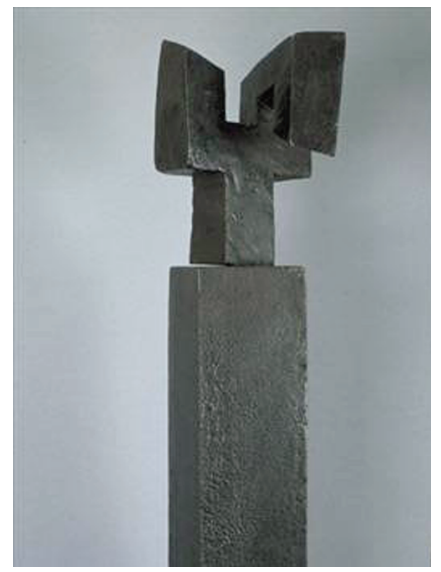

Ilarik. Piedra funeraria

El espíritu, una materia rapidísima (...), la materia, eso, un espíritu lento. ${ }^{33}$

\section{El proceso creador en Eduardo Chillida}

El proceso creador se inicia con lo que Chillida denomina "aroma"; es una especie de preconocimiento, no es un azar sino que es un don:

${ }^{32}$ Ugalde 1975, op. cit. (nota 4) p. 136.

${ }^{33}$ Ibidem, p.134. 
Lo mío es como una aventura en lo desconocido que va atrayendo un quehacer en espiral que es mi obra y este presentimiento que camina en esa dirección con todo su cuerpo va atraído por una especie de fe, lo que yo llamo un "aroma", algo que está más allá de los cinco sentidos y que me guía hacia la realización... Yo conozco mi obra desde el comienzo, conozco la obra desde atrás, pero no sé cómo es hacia adelante, hacia donde me va a llevar esta aventura. ${ }^{34}$

En este proceso el artista pasa por una "angustia creacional" percibida por él como un proceso, como el paso por unos territorios muy oscuros pero necesarios. Sitios nada cómodos, espinosos, llenos de trampas. Pero en esos recorridos que son expuestos, siente que le acompaña y le guía siempre la esperanza de que ese subterráneo conduce a una luz, la creación de la obra. Esa creación de la obra es

Arrancar, a veces uno no sabe dónde. Yo comienzo una escultura por el corazón (...), ya con este latido no me siento solo, y es esta compañía la que me impulsa a caminar en la dirección de eso que el poeta René Char llamaba "la noche", esa noche contra la que tiene que caminar el artista, siempre la frente pegada a lo desconocido, valiéndome de mi "mano", de mis dos manos..$^{35}$

La mano, las dos manos, prolongación más directa del cerebro, muy próximas al corazón, son las que construyen la obra,

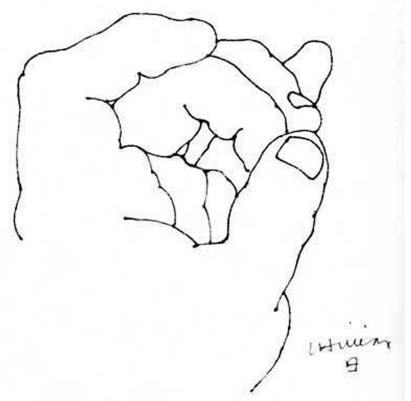

Manos. Dibujo

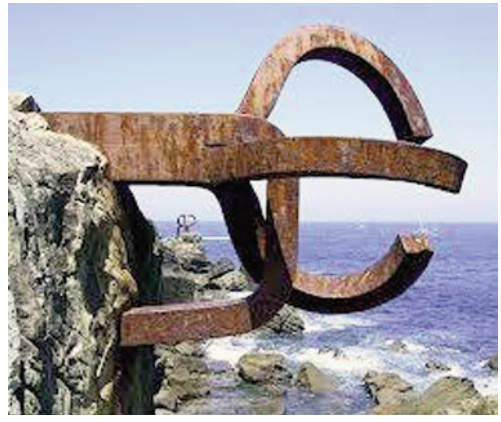

Peine del viento

\footnotetext{
${ }^{34}$ Ibidem, p. 134.

${ }^{35}$ Ibidem, p. 131.
} 
Lo que importa es ese pájaro que vuela de los cien que hay y, de ese pájaro único, lo que me importa más no es el pájaro mismo sino su vuelo. ${ }^{36}$

Lo que importa también es esa mano que crea la obra. La obra no es un resultado al que se tiene acceso de cualquier manera sino que

La obra es una manera de fraguar, de materializar mis preguntas... ${ }^{37}$

Existen leyes que deben conducir a un punto determinado y caminos que son óptimos y otros que no lo son,

Hay un camino óptimo y ese camino óptimo es el camino ético; y, claro, un camino que tiene acceso a la estética también. Y, en todo este proceso doy una valoración extrema a la libertad..$^{38}$

Chillida considera que la obra verdadera debe partir de una situación de libertad, libertad que valora de manera extrema:

No admito posibilidad alguna de obra, de obra de arte, que no esté fundada sobre una gran libertad (...) sin que esto no quite para que yo sepa que esta libertad me la tengo que limitar; siento que la justicia, el amor, la solidaridad, no deben ser atropelladas por mi libertad. ${ }^{39}$

Respecto a su trabajo afirma que el origen está en descubrir, ver por primera vez una cosa pero con una mirada más profunda que permite descubrir lo que hay mucho más allá de la apariencia superficial; sin embargo, no por ello cae forzosamente en la abstracción,

No soy abstracto sino realista...

La diferencia con otros realistas,

Yo he rechazado las apariencias ${ }^{40}$.

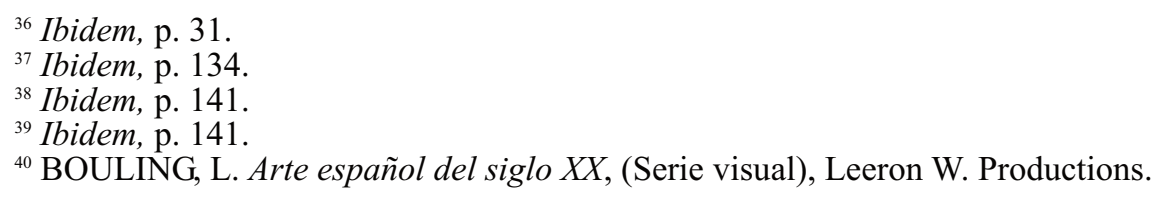


Se debe tener en cuenta además, de qué forma se genera a veces su obra en la que inciden consideraciones de un orden hermético, pero de un hermetismo no voluntario. Hay espacios que desaparecen pero afirma,

Los únicos ojos para los que no han desaparecido estos espacios que han quedado prisioneros (...) es a los míos; porque yo los he hecho, yo sé lo que pasa ahí dentro, pero nadie más lo sabe. ${ }^{41}$

La única comunicación del espectador con lo que pasa dentro se produce a través de las referencias, las consecuencias aparentes, lo que ha quedado a la vista. Se descubren fuera una serie de leyes que hacen imaginar lo que pasa ahí dentro. No se trata de un ocultamiento o hermetismo voluntario sino de una consecuencia del trabajo mismo, de su propia inspiración interior y de su evolución.

Cuando en el terreno de la comunicación del arte con la sociedad me preguntan (...) para quién trabajo yo, cuáles son los fines de mi obra con relación al mundo actual, o a la sociedad, o al hombre, yo suelo decir que yo trabajo para mí porque yo me considero una parte de la sociedad, y la que tengo más cerca, más a mano, y yo me tengo que dirigir a mí mismo para poder llegar a los demás hombres, puesto que yo soy uno de tantos... ${ }^{42}$

Chillida, calificado como un solitario, afirmaba que todos estamos un poco solos. El que está más solo busca más la comunicación y esa sed de comunicación ha guiado su obra.

He sentido radicalmente, profundamente, todo lo que implica este difícil fenómeno de la exteriorización de lo que uno piensa y la manera de hacer que este medio que improvisa uno como puede, como sea capaz, llegue con la menor distorsión posible a los demás. ${ }^{43}$

Reconoce que desde muy joven sintió que su obra no estaba destinada a él solo aunque, a la vez, sabía que debía dirigirla hacia sí mismo, es decir, a través de sí mismo encontraría el camino para llegar a los demás.

El lenguaje de comunicación que ha ido construyendo el hombre lentamente ha tenido una tendencia natural e inteligente hacia la abstracción, hacia la compren-

${ }^{41}$ Ugalde 1975, op. cit. (nota 4) p. 149.

${ }^{42}$ Ibidem p. 64.

${ }^{43}$ Ibidem, p. 63. 
sión y expresión de la realidad que es en sí misma compleja. El lenguaje del hombre inteligente ha ido evolucionando hacia la mayor participación de una facultad más alta, la imaginación, y esto mediante una natural acumulación cultural. De una manera semejante ha ido evolucionando el lenguaje artístico en los distintos campos. El artista de hoy no puede expresarse con un lenguaje que es de ayer, que es un vehículo de comunicación que ya está agotado, si quiere de verdad hablar a la gente que piensa en los términos que están en el lenguaje de nuestros días. Antes, el espectador de una obra de arte era un elemento pasivo, receptor. Hoy se le exige además de una sensibilidad más cultivada, un trabajo de estudio que requiere una cierta información y una cierta cultura porque los lenguajes evolucionan constantemente hacia formas más altas, más capaces de expresión, de comunicación interior. Esto ocurre en literatura, pintura, música... en todas las manifestaciones del arte.

\section{Respuestas. La obra y sus elementos constitutivos.}

Chillida en los años cincuenta sufre este importante cambio en el lenguaje de su obra que supuso para él una importante crisis,

El camino ascendente siempre es difícil y doloroso. Yo me imagino siempre este desprendimiento interior que fue mi crisis grande como si hubiese ocurrido un desprendimiento de tierra, algo que no tiene remedio, algo de lo que ya no se puede volver atrás... ${ }^{44}$

A lo largo de este camino de artista se define como un hombre que se hace muchas preguntas afirmando que un escultor es

Un hombre que sabe muy pocas cosas pero que se hace muchas preguntas. Yo me he pasado toda la vida preguntándome (...). Quizá la escultura sea la sugerencia de una respuesta a una pregunta que el escultor se ha hecho y que el espectador debe advertir sin desvelar. ${ }^{45}$

A la vez que se responde

No sé hasta qué punto mis obras pueden ser consideradas como respuestas a estas preguntas. Yo siento por todas partes los peligros de descansar

\footnotetext{
${ }^{44}$ Ibidem p. 73.

${ }^{45}$ Chillida 1992, op. cit. (nota 2), pp. 52-53.
} 
en algo que pueda parecer una respuesta, porque sé íntimamente que no hay respuestas concretas y definitivas; que el hombre no es hombre, ni el artista, artista, si no es en ese límite del desafío de lo inseguro, y es con ellos, con estos peligros, con los que avanzo... ${ }^{46}$

La realidad es el punto de partida. De lo conocido a lo desconocido.

En el interior de las cosas que estoy mirando hay cantidad de cosas que soy incapaz de ver. ${ }^{47}$

Hay para Chillida una realidad que no es física, que está contra las leyes físicas pero que es real. Tal es el caso de esas esculturas suspendidas en las que parece que se ha invertido el problema: parecen apoyadas en el vacío como si éste las sustentase. Es como una contra-impresión. Todo parece invertido. Como una gran densidad que rodea un gran vacío. Algo difícil de explicar a nivel racional pero que consigue comunicarse,

También dentro de lo conocido se haya lo desconocido. Contra orientación y estabilidad y conocimiento: desorientación, inseguridad, asombro. (...) Nunca lo establecido podrá cerrar el paso a aquello que va a nacer (...).

Si yo hago la escultura que hago es para tratar de explicar cosas que no se pueden explicar de otra manera. ${ }^{48}$

Todo su trabajo está saturado de un profundo respeto hacia la materia, su comportamiento, su conducta. Dominar la materia es parte fundamental de su trabajo pero, dominarla de manera respetuosa, no tiránica, en una relación constante que la hace depender del tiempo y de la velocidad,

El espíritu, una materia rapidísima (...), la materia, eso, un espíritu lento. ${ }^{49}$

El espacio es otro componente de la obra. Chillida considera este concepto desde distintos puntos de apreciación. Espacio sin nombre que abarca todos los espacios. El "espacio positivo" o volumen real de la obra y el "espacio negati-

\footnotetext{
${ }^{46}$ Ugalde 1975, op. cit. (nota 4) p. 134.

${ }^{47}$ BOULING op. cit. (nota 28).

${ }^{48}$ Ugalde 1975, op. cit. (nota 4) pp. 90, 91 y 95.

${ }^{49}$ Ibidem p. 107.
} 
vo" o espacio contenido dentro de la obra. Espacio como lugar de encuentros. Espacio, hermano del tiempo.

Espacio y materia se relacionan como dos elementos necesarios en escultura pero que generan relaciones totalmente distintas en cada materia:

Mi manera de acercarme al hierro es abrazando el espacio. Siempre es una lucha entre el hierro y el espacio, pero siempre el hierro está abierto en relación con el espacio. El espacio comprometido con la obra es el espacio que la rodea.

En el alabastro el problema es completamente distinto. El espacio está en el interior de la obra y entonces tienes el vacío en el corazón de la piedra. En la tierra, un bloque de tierra es ya un universo. El espacio que lo rodea ya es otro problema pero dentro está ocurriendo algo, en el centro de ese universo que está limitado por la forma de esa tierra. ${ }^{50}$

A veces parece que lo que se ve en la forma escultórica de Chillida es más la propia presencia del material que tal o cual forma. Cuando, por el contrario, en otros artistas, dos esculturas con forma idéntica y distintos materiales son intercambiables. Chillida, trabajando una materia la "escucha" sabiendo que esa materia es adecuada para determinadas cosas y, en cambio, no lo es para otras. A lo largo de los años trabajó distintos materiales, el yeso, la piedra, el granito, madera, alabastro...

He trabajado la madera, pero mi interés por ella cedió cuando terminé los Abesti gogorra que están en los museos americanos. Eran de gran formato y me sirvieron para expresar el proceso de relación entre lo grande y lo pequeño, lo lleno y lo vacío, cosa que no se podía hacer en hierro a gran escala. Empecé a notar que los espacios cerrados de la madera se hacían inaccesibles, que no podía trabajar en ellos, y pasé a otra cosa (...). El alabastro es la luz. Ha sido la luz lo que me ha acercado al alabastro (...). El encuentro con esa luz (la luz clara del Mediterráneo expresada en el arte clásico griego) fue lo que me condujo a los alabastros. Es el problema de uno que pertenece a la luz negra y valora lo que es la luz blanca (...). Me encontraba un poco perdido cuando me topé con el hierro y todo cambió mucho respecto a mis primeras obras. El hierro es duro, es agresivo, es ora luz, la luz negra, y me hace abandonar la luminosidad de esas obras primerizas de París. Sucedió sencillamente que yo pertenecía a este

${ }^{50}$ BOULING, L. Arte español del siglo XX, (Serie visual), Leeron W. Productions 
país (...), esta luz no es la luz del Mediterráneo (...), no es la luz de Grecia, aquella luz blanca (...), nosotros somos hijos de otra luz. Una luz oscura, una luz distinta, negra, misteriosa (...). Es una cultura oceánica y mítica, con una luz que invita a otra forma de mirar. ${ }^{51}$

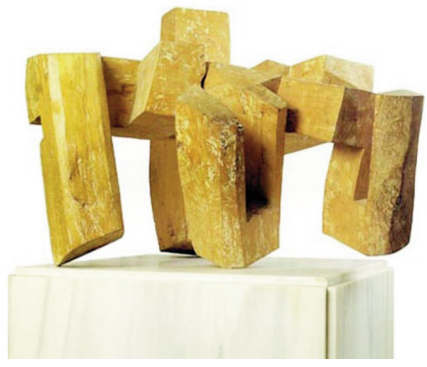

Abesti Gogora IV Madera

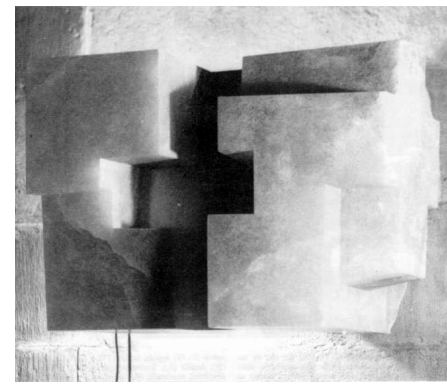

Elogio de la luz. Alabastro

Por esta razón el hierro es un material fundamental en la obra de Chillida. El suyo es un cosmos de hierro donde, mientras la piedra es masa, el hierro es músculo. Esa luz oscura a la que pertenece es la de su tierra vasca. Su obra de hierro a partir de Ilarriak saca puntas al hierro para desgarrar el aire recordando la laya y el arado claves del caserío vasco. Lo mismo cabría decir de Intzenea que Gabriel Celaya liga a esos arquetipos de la conciencia arcaica vinculada al "habitat de las cavernas y de las materias inmemoriales" 52 . También Claude Esteban cuando se refiere a Ikaraundi (temblor grande) y a Aizian (en el viento), alude a este mismo aspecto del lenguaje vasco de Chillida.

El hormigón, por otra parte, es un material muy "pensado" por Chillida durante mucho tiempo antes de su aplicación en 1972. Pensaba en un hormigón con un sentido diferente al habitual y sería de hecho el primer escultor que realiza esculturas suspendidas en hormigón, los Leku o Lugar de encuentro.

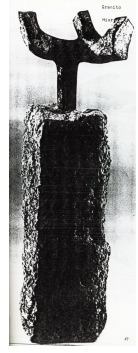

Yunque de sueños. Hierro y granito

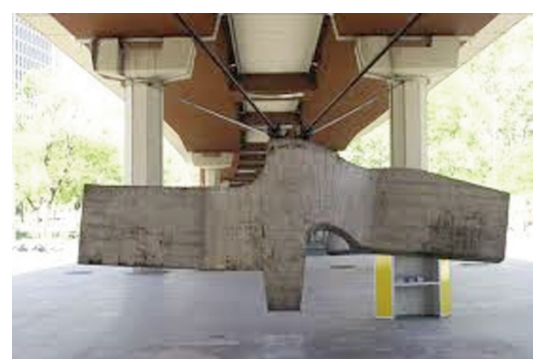

Lugar de Encuentro. Hormigón

${ }^{51}$ Chillida 1992, op. cit. (nota 2) pp. 52-53.

${ }^{52}$ Celaya, G., Los espacios de Chillida, Barcelona, 1974. 
Son estos hormigones míos aparentemente muy similares a otros que se fabrican, pero que, aparte de condiciones de resistencia y demás que yo exijo a estas esculturas suspendidas, son de unas cualidades especiales... ${ }^{53}$

La levitación será en estas obras la inversión del problema del espacio en la relación peso-gravedad. Se trata de la oposición a la fuerza de la gravedad por la sustentación en el espacio de elementos con numerosos puntos de atracción, es decir, elementos muy pesados, al revés de lo que tradicionalmente se venía haciendo al afrontar este problema con piezas ligeras.

En el trato con la materia el fuego es fundamental como medio para transformar la materia. Si el hierro está frío es imposible trabajarlo, doblegarlo. Pero con el fuego una gran masa de hierro acepta la posibilidad del movimiento. Esta es su manera intuitiva de entender la conexión del fuego con el hierro.

En cuanto a la monumentalidad que podría emparejarse con materiales como el hormigón, por ejemplo, en el caso de Chillida esta monumentalidad no llegó con el hormigón sino que ya apuntaba en esta dirección el trabajo en madera del año 1959. Realizó grandes obras de roble de hasta 3000 kilogramos de peso (Abesti gogorra). A través de esa monumentalidad de la madera trataba de cambiar los módulos de relación entre el espacio positivo, espacio negativo y espacio real que envuelve a la obra. Hay además, una razón de tipo social: ante el encarecimiento de su obra, Chillida realiza a veces obras monumentales para que se sitúen en lugares públicos,

Una obra (...) que por su tamaño tenga que ser necesariamente pública. (...) La escultura que pertenece al lugar que es de todos. ${ }^{54}$

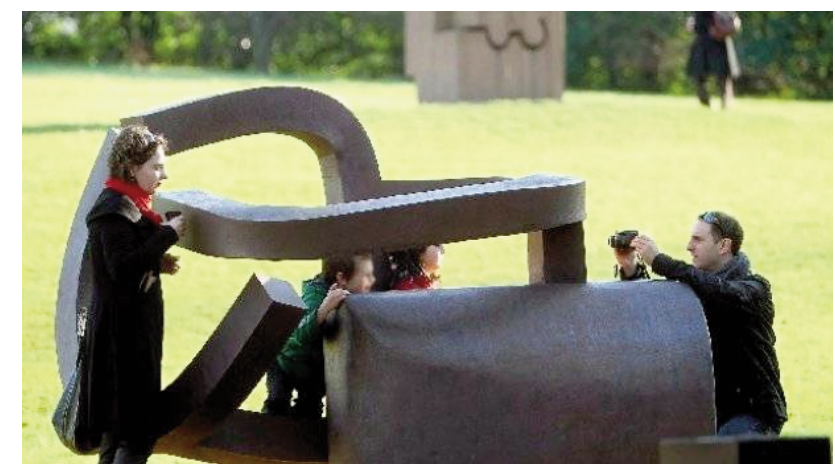

${ }^{53}$ Ugalde 1975, op. cit. (nota 4) p. 51.

${ }^{54}$ Ibidem, p. 84. 
Después habrá otros materiales como el acero, el plomo, el papel de dibujar y el collage, la xilografía, la piedra litográfica, el cobre del grabador. Pero materiales usados en escultura propiamente, son los anteriores.

El espacio y el espacio materializado, ocupado por una materia con la que se vincula, se relaciona directamente con el problema de los límites. ¿Qué son los límites para Chillida? Esos linderos que se pueden palpar. El litoral donde la tierra y el mar se encuentran y donde intercambian, sobre la línea extrema del horizonte -el presente de nuestra experiencia- sus calidades y sus sustancias. Los límites son extremos.

El diálogo limpio y neto que se produce entre la materia y el espacio, la maravilla de ese diálogo en el límite, creo que, en una parte importante, se debe a que el espacio, o es una materia muy rápida, o bien la materia es un espacio muy lento. ¿No será el límite una frontera, no solo entre densidades, sino también entre velocidades? $?^{55}$

En el límite se mide también el tiempo. El misterio del tiempo, de la duración, está en la obra de Chillida. El hecho misterioso de la no dimensión del presente, que es donde todo ocurre. La consideración del pasado y el futuro como contemporáneos. En un proceso medido y experimentalmente lento, Chillida elabora un lenguaje, de lo figurativo a lo abstracto, capaz de tratar estos problemas que suponen un alto nivel de abstracción.

La densidad tiene que ver tanto con la materia como con el límite o el tiempo. Es un concepto clave que no es material pues Chillida no se refiere a densidad de color o de masa. La densidad para él no es nada material sino concentración de tiempo, de espíritu: concentración de límites, demarcación de esfuerzo, limitación de propósito, del comportamiento asumido y comprometido. Todo eso es lo que da a la obra densidad. Todo lo demás, la libertad amplia, fácil, sin límites, la alegre facilidad, no da densidad.

Las obras densas tienen ese factor común que tú puedes analizar después, a posteriori, en las vidas (...) y en el comportamiento a cualquier nivel de mucho artistas. ${ }^{56}$

${ }^{55}$ Chillida 1994, op. cit. (nota 1), pp. 49-50.

${ }^{56}$ Ugalde 1975, op. cit. (nota 4) p. 41. 


\section{Conclusión}

¿Qué es Chillida? ¿Qué fue Chillida? La teoría de Clement Greenberg, autor de numerosos artículos sobre pintura y escultura americanas entre 1940 y 1970, dice que desde mediados del siglo XIX las artes adquirieron conciencia de que el único modo de salvarse de su fatal destino era demostrando que la clase de experiencia que proporcionaban era valiosa por derecho propio y no obtenida de cualquier otro tipo de actividad. Cada arte debía demostrarse sobre sus propias bases. Debía determinar lo que tenía de peculiar y exclusivo, reduciendo su área de competencia, pero, al mismo tiempo, haciendo esta área más segura. Esto llevó a la "pureza", a la eliminación de todo aquello que se hubiera tomado de otras artes.

Según estos criterios, ¿Cuál sería la posición de Chillida? Chillida es un escultor "puro" frente a la contaminación de otros medios que puede darse en otros artistas, entendiendo "puro" en el arte moderno como una búsqueda de lo que es específico y propio de cada arte. Pero, ¿hay realmente una escultura moderna reconocible como tal? ¿Es Chillida uno de sus representantes o simplemente coincide con ella en algo?

Greenberg presenta una concepción reduccionista del arte moderno, además de esencialista. Seguramente es más interpretable Chillida en estos términos. No se identifica con jóvenes airados que desafían ruidosamente a sus mayores. ¿Es Chillida entonces un continuista? ¿De qué es continuista, si lo es? Y, si hay ruptura, ¿Dónde está? Puede que falte en este sentido un análisis de la escultura de Chillida sobre las bases críticas empleadas para todo el arte moderno. ¿Quién ha patrocinado a Chillida? ¿Quién ha sido su crítico? ¿Quién le ha incluido en el mundo artístico de su época? ¿Con qué otros artistas se relacionaba? ¿Cuál es el verdadero papel internacional de Eduardo Chillida? ¿Es un marginal de las historias de la escultura moderna donde tras Moore viene Smith y tras Smith, Caro y tras Caro...? ¿Cuál es el lugar que se reserva para los artistas más individuales como Wright, Picasso, Chillida?

Además de haber sido él "un hombre que se hace muchas preguntas", son también muchas las preguntas que quedan aún por responder. Verdaderamente Eduardo Chillida es -fue- un hombre muy fuerte.

El arte actual se caracteriza por una generalizada hibridación en las obras. Los 90 retoman una vez más lo que fue característico de los 50 y 60: hibridación artística. De la abstracción con la expresión, de los géneros artísticos entre sí; de la pintura con la escultura, de éstos con la narrativa, el cine, el video... ¿Qué puntos de contacto tendría la obra de Chillida con esta instantánea? ¿Se da también en su obra esta permeabilidad o coexistencia de lo abstracto con lo expresivo, de la abstracción con la emoción? 
Ante estas cuestiones cabría afirmar la permanencia como un rasgo destacable en la escultura de Chillida. Esa evolución interna caracterizada por los cambios de dirección, la ruptura de sus propios dogmas, la ironía sobre su camino anterior, las antítesis, los contrastes... algo frecuente en otros artistas, no parece darse en él. Es la permanencia de Chillida frente a esa algarabía paracomercial, la permanencia y la fuerza de "un corredor de fondo", como se definió a sí mismo en algún momento,

Verdaderamente Eduardo es un hombre muy fuerte, y no solo físicamente, manteniendo el tipo, impasible ante la secuencia de mamarrachadas de galería. Habrá capítulos diversos en la obra de Chillida pero al lado de las cosas que he señalado, yo indicaría, frente a esas situaciones penosas, la de la coherencia, por encima de las alteraciones lógicas en la respiración espiritual, la anti-frivolidad. ${ }^{57}$

${ }^{57}$ Fullaondo, J. D. Laoconte crepuscular: conversaciones en torno a Eduardo Chillida, Madrid, Kain Editorial, 1991, p.56. 